\title{
Case report: adult onset diabetes with partial pancreatic agenesis and congenital heart disease due to a de novo GATA6 mutation
}

Begona Sanchez-Lechuga ${ }^{1 *}$, Muhammad Saqlain², Nicholas $\mathrm{Ng}^{1}$, Kevin Colclough ${ }^{3}$, Conor Woods ${ }^{2}$ and Maria Byrne ${ }^{1}$

\begin{abstract}
Background: Mutations in GATA6 are the most frequent cause of pancreatic agenesis. Most cases present with neonatal diabetes mellitus.

Case presentation: The case was a female born after an uncomplicated pregnancy and delivery in a nonconsanguineous family $(3.59 \mathrm{~kg}$, 70th percentile). Severe cardiac malformations were diagnosed at two and a half months old. No hyperglycaemic episodes were recorded in the neonatal period. Diabetes was diagnosed at 21 years due to the detection of incidental glycosuria. She had a low but detectable C-peptide level at diagnosis. AntiGAD and Islet-cell antibodies were negative and she failed oral hypoglycaemic therapy and was started on insulin. Abdominal MRI revealed the absence of most of the neck, body, and tail of pancreas with normal pancreas elastase levels. Criteria for type 1 or type 2 diabetes were not fulfilled, therefore a next generation sequencing (NGS) panel was performed. A novel heterozygous pathogenic GATA6 mutation (p.Tyr235Ter) was identified. The GATA6 variant was not detected in her parents, implying that the mutation had arisen de novo in the proband.

Conclusion: Rarely GATA6 mutations can cause adult onset diabetes. This report highlights the importance of screening the GATA6 gene in patients with adult-onset diabetes, congenital cardiac defects and pancreatic agenesis with no first-degree family history of diabetes. It also emphasizes the importance of genetic counselling in these patients as future offspring will be at risk of inheriting the variant and developing GATA6 anomalies.
\end{abstract}

Keywords: Adult-onset, Diabetes, GATA6, Pancreatic agenesis, Treatment

\section{Background}

The formation of beta-cells during embryonic development is regulated by several transcription factors (TFs) that activate specific genes. Many of these TFs are also important in pancreas function during adult life [1]. The GATA family represents a group of conserved zinc

\footnotetext{
* Correspondence: bsanchezle@gmail.com

${ }^{1}$ Department of Diabetes \& Endocrinology, Mater Misericordiae University Hospital, Dublin 7, Ireland

Full list of author information is available at the end of the article
}

finger TFs involved in development and differentiation of eukaryotic organisms. Two subgroups have been described in vertebrates, including the hematopoietic GATA1/2/3 and cardiac groups GATA 4/5/6 [2]. This last group is expressed in tissues of endodermal and mesodermal origin including gut, lung, heart and pancreas [3]. Mutations in GATA6 are the most frequent cause of pancreatic agenesis $[4,5]$. It is also associated with neonatal diabetes mellitus (NDM), congenital cardiac malformations and other extrapancreatic features

C C The Author(s). 2020 Open Access This article is licensed under a Creative Commons Attribution 4.0 International License, which permits use, sharing, adaptation, distribution and reproduction in any medium or format, as long as you give appropriate credit to the original author(s) and the source, provide a link to the Creative Commons licence, and indicate if changes were made. The images or other third party material in this article are included in the article's Creative Commons licence, unless indicated otherwise in a credit line to the material. If material is not included in the article's Creative Commons licence and your intended use is not permitted by statutory regulation or exceeds the permitted use, you will need to obtain permission directly from the copyright holder. To view a copy of this licence, visit http://creativecommons.org/licenses/by/4.0/. The Creative Commons Public Domain Dedication waiver (http://creativecommons.org/publicdomain/zero/1.0/) applies to the data made available in this article, unless otherwise stated in a credit line to the data. 
such as biliary tract defects, gut abnormalities $[4,6]$ and significant neurocognitive deficit $[5,7]$. The most common pancreatic feature is diabetes occuring in $98 \%$ of cases. The vast majority of cases present with NDM, but a small proportion develop adolescent or adult onset diabetes [7].. This report describes a 21 year old female diagnosed with adult-onset diabetes associated with congenital heart defects and pancreatic agenesis associated with a de novo heterozygous mutation in the GATA6 gene.

\section{Case presentation}

She was born at 40 weeks gestation after an uncomplicated pregnancy and delivery in a non-consanguineous family. Her birth weight was $3.59 \mathrm{~kg}$ (70th percentile). She was diagnosed with a severe cardiac malformation (subaortic ventricular septal defect, small atrial septal defect and moderate patent ductus arteriosus) at two and a half months old. At 5 months old, coartation repair, PDA ligation and pulmonary artery banding were performed. Some months later she had the VSD repaired and pulmonary artery deep banding. She had mild residual coarctation, bicuspid aortic valve with mild aortic stenosis and mild aortic incompetence. She had normal growth with adult height of $165 \mathrm{~cm}$. She also had scoliosis and hypertension (on losartan $100 \mathrm{mg}$ ). She completed secondary school and works as a health care assistant. No hyperglycaemic episodes were recorded in the neonatal period. At 21 years old, incidental glycosuria was detected and diagnosis of diabetes was confirmed. Baseline fasting bloods showed glucose $9 \mathrm{mmol} /$ l, Insulin $19.7 \mathrm{mUI} / \mathrm{l}(2-25)$ and C-peptide $2.8 \mu \mathrm{gr} / \mathrm{l}$ (1.1-4.1). HbA1c was $61 \mathrm{mmol} / \mathrm{mol}$, and anti-GAD and Islet cell antibodies were negative. Pituitary and thyroid function were normal. On examination, BP was 102/72 $\mathrm{mmHg}, \mathrm{HR} 74 \mathrm{bpm}$ and BMI was $24.3 \mathrm{~kg} / \mathrm{m} 2$. She has no features of insulin resistance: no striae, acanthosis nigricans or skin tags. She had a $2 / 6$ aortic ejection systolic murmur with a $2 / 4$ early diastolic murmur. Significant scoliosis was noted. She was started on metformin, but this was discontinued due to gastrointestinal side effects, and gliclazide MR $30 \mathrm{mg}$ once daily was started. There was a positive family history of diabetes shown in Fig. 1. There was no family history of cardiac defects or

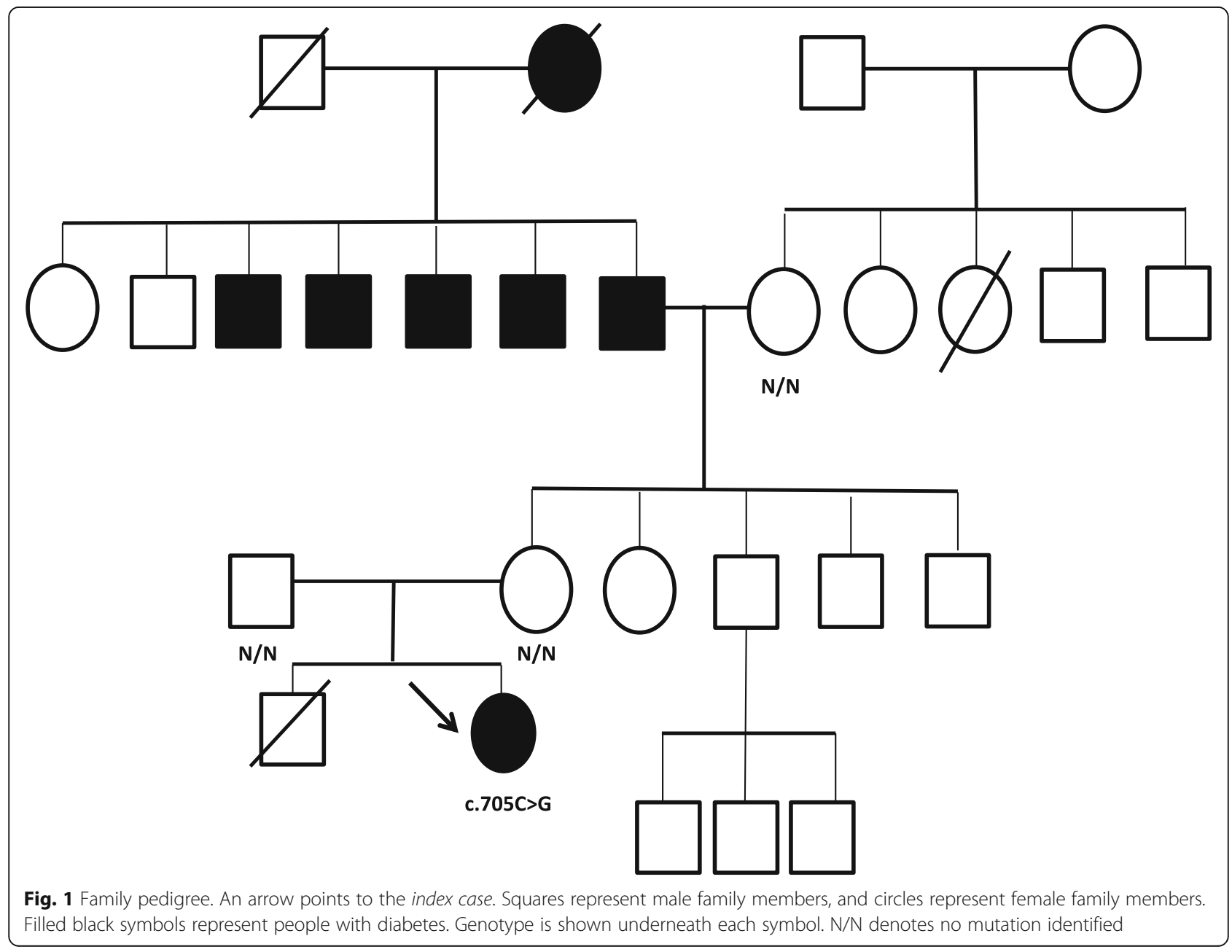


pancreatic agenesis. Her mother reported a still birth at 7 months before the index case was born (unknown cause of death).

She was referred with atypical diabetes to the maturity onset diabetes of the young (MODY) clinic in 2017 with a HbA1c of $59 \mathrm{mmol} / \mathrm{l}$ on gliclazide which was increased to $60 \mathrm{mg}$ daily. An oral glucose test was performed (14 months after diagnosis) off treatment for 2 days. Fasting glucose was $10.3 \mathrm{mmol} / \mathrm{l}$ and her 2 -h post load glucose was $18.4 \mathrm{mmol} / \mathrm{l}$; fasting C-peptide was $484 \mathrm{pmol} / \mathrm{l}$ and $2 \mathrm{~h}$ post load was $512 \mathrm{pmol} / \mathrm{l}$. Subsequently, gliclazide MR was titrated to $120 \mathrm{mg}$ daily. Three months later blood glucose level was $32 \mathrm{mmol} / \mathrm{l}$ (HbA1c $95 \mathrm{mmol} /$ mol) and gliclazide was discontinued. Multiple dose injection therapy was started. Her current HbA1c is 45 $\mathrm{mmol} / \mathrm{l}$ on 25 units of insulin daily. Incidentally, during investigations for other disorders, an abdominal magnetic resonance imaging revealed the absence of most of the neck, body and tail of pancreas (Fig. 2). Pancreas elastase was $>500 \mu \mathrm{g} / \mathrm{g}$ (normal $>200 \mu \mathrm{g} / \mathrm{g}$ ). She had no evidence of background retinopathy and her microalbuminuria to creatinine ratio was normal.

Patient did not meet criteria for either type 1 or type 2 diabetes and was categorized as "Other diabetes". A mutation in hepatocyte nuclear factor $1 \mathrm{~B}$ was suspected initially given her diabetes profile and pancreatic agenesis. A renal and pelvic ultrasound scan was performed and no abnormality was detected. Targeted NGS analysis of 34 known monogenic diabetes genes identified a novel heterozygous pathogenic GATA6 nonsense variant, (p.Tyr235Ter) (NM_005257.5:c.705C > G) in exon 2. This variant is classified as pathogenic class 5 according to the AMCG guidelines [8]. The variant generates a premature termination codon in exon 2 and the mRNA transcripts are predicted

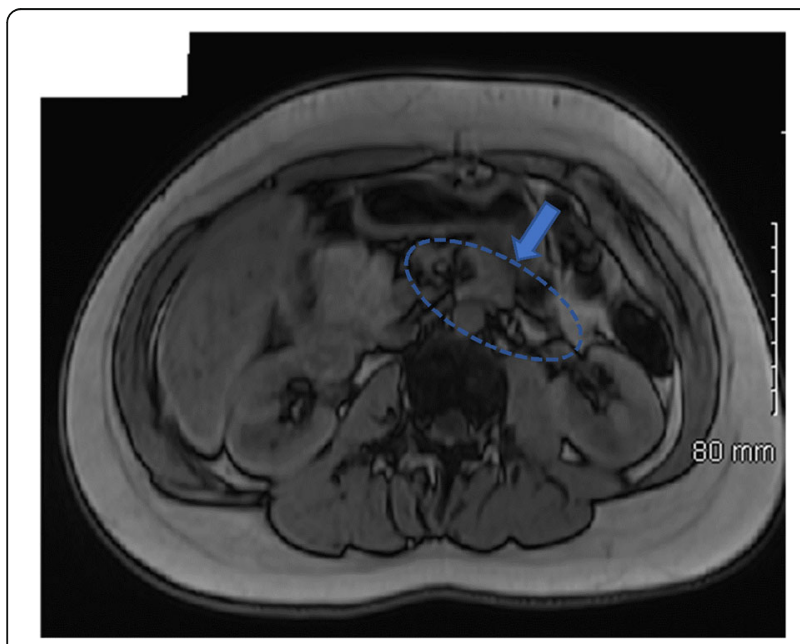

Fig. 2 Abdominal MRI axial and coronal image revealing the absence of most of the neck, body and tail of pancreas to undergo nonsense mediated decay, resulting in haploinsufficiency for GATA6 (Fig. 3).

The GATA6 variant was not detected in peripheral blood samples from her non diabetic parents (mother HbA1c $28 \mathrm{mmol} / \mathrm{mol}$, FPG $3.9 \mathrm{mmol} / \mathrm{l}$ and father $\mathrm{HbA} 1 \mathrm{c}$ $37 \mathrm{mmol} / \mathrm{mol}$, FPG $5.5 \mathrm{mmol} / \mathrm{l}$ ) and maternal grandmother (Fig. 1), implying that the mutation had arisen de novo in the proband. Low level somatic mosaicism in both parents was excluded to a level of $\geq 5 \%$. The possibility of germline mosaicism could not be excluded.

\section{Discussion and conclusion}

This report describes a 21 year old female diagnosed with adult-onset diabetes associated with atrial septal defect, subaortic ventricular septal defect, patent ductus arteriosus and pancreatic agenesis and a novel de novo heterozygous mutation (p.Tyr235Ter) in the GATA6 gene.

Pancreatic agenesis is a rare disorder resulting in NDM associated with exocrine pancreatic insufficiency [9]. The commonest cause of pancreatic agenesis or hypoplasia is heterozygous inactivating mutations in GATA6 $[5,7,10]$.. The prevalence of GATA6 mutations is unclear but a few studies have shown that mutations account for at least $3 \%$ of NDM and $54 \%$ of patients with pancreatic agenesis [5]. The most common phenotypes are congenital cardiac defects, particularly outflow tract malformations such as atrial and ventricular septal defects or tetralogy of Fallot [4]. GATA6 mutations can also lead to several other phenotypes: congenital biliary tract anomalies $(17 \%)$, gut developmental disorders $(21 \%)$, neurocognitive $(38 \%)$ and additional endocrine abnormalities (24\%, hypothyroidism/hypopituitarism) [4, 5, 7].

Pancreatic agenesis or hypoplasia can cause permanent NDM and has been associated with mutations in TFs important for $\beta$ cell and pancreatic development., GATA6 is the most common of these mutations [11].. The severity of diabetes varies among family members, ranging from NDM with only a remnant of pancreatic tissue to adult-onset diabetes associated with dorsal agenesis of the pancreas [12-14]. The mechanism whereby GATA6 mutations result in associated clinical phenotypes is still not completely understood.. The mutation (p.Tyr235Ter) in the GATA6 protein occurs in the transcriptional activation domain which is full of pathogenic variants. There are multiple nonsense mutations close by and even a missense mutation on the same amino acid. A recent publication by Škorić-Milosavljević et al. [15], highlights the broad mutational and clinical spectrum and lack of genotype-phenotype correlation in patients with GATA6 mutations. Their study showed that $58 \%$ of probands had de novo mutations and these patients had more frequently anomalies of intracardiac connections and the great arteries and they were more likely to have hypothyroidism when 


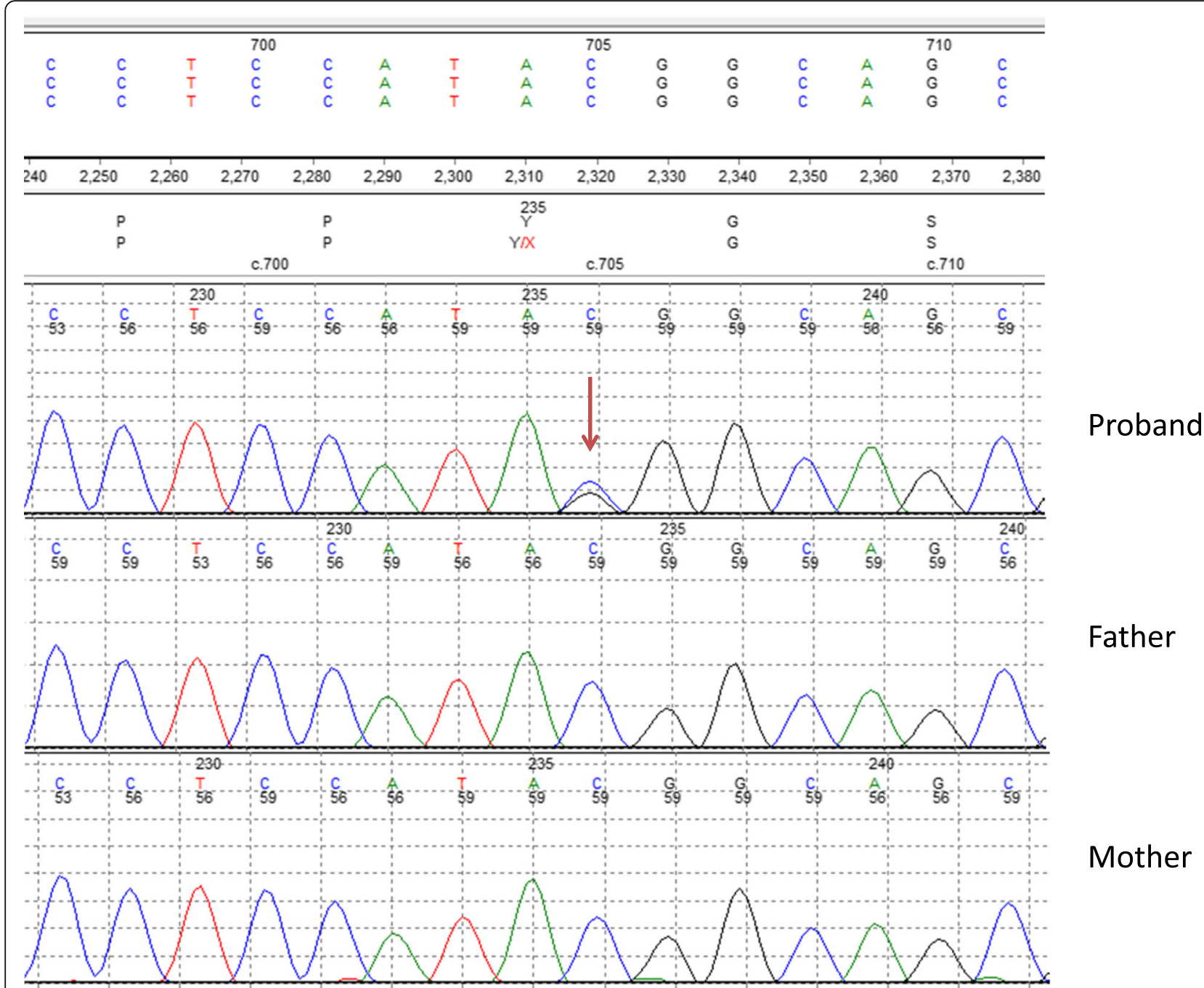

Fig. 3 Sanger sequencing electropherogram of GATA6 exon 2 showing the heterozygous C > G single base substitution at nucleotide position 705 (c.705C > G) resulting the nonsense variant (p.Tyr235Ter) in the proband. The variant is absent in electropherograms from mother and father. Sanger sequencing is able to detect low level somatic mosaicism to a level of approximately $5-10 \%$

compared to patients who had inherited a mutation. Our patient did not have hypothyroidism. The phenotypic spectrum suggests the existence of modifier genes. This is a syndromic disorder, and therefore by its nature will have a variable clinical phenotype and penetrance just as we see with other dominantly inherited syndromic forms of diabetes such as HNF1B where there is no genotype-phenotype correlation [16].

De Franco et al. [5] found that while investigating 171 patients with neonatal diabetes, four parents with heterozygous GATA6 mutations (c.1136-2A > G, p.(Tyr323*), p.(Thr346fs) p.(Gly469Glu), were diagnosed with adolescent or adult-onset diabetes (12-46 years). A retrospective study for pancreatic donors with diabetes showed a 16 years old girl diagnosed with GATA6 mutation p.(Arg456Cys) and adolescent-onset diabetes [14]. It remains unclear if environmental factors or the different genetic background of other genes can interact with GATA6 [13]. Reviewing the literature, a de novo mutation in GATA6 p.(Arg456His) was recently shown to be associated with young adult-onset diabetes type 1 at age 22 in a patient with pancreatic hypoplasia [15]. The other two patients with adolescent or adult-onset diabetes (c.1504_1505delAA) were detected due to investigations for family members with neonatal diabetes [13]. The mutations do not represent a separate class. Summarizing, it has been described a total of 3 adolescents and 5 adults onset diabetes. Interestingly, our patient did not show growth retardation or failure to thrive. In addition, her faecal elastase levels were normal and she only developed diabetes at age 21 years. This is consistent with a previous report of phenotypic heterogeneity ranging from pancreatic agenesis to adult onset diabetes with no evidence of exocrine pancreatic insufficiency [5]. Her findings are consistent with dorsal pancreatic agenesis as previously 
described in patients with adolescent or adult onset diabetes with GATA6 mutations [12, 13]. Interestingly, she failed sulphonylurea therapy and required insulin within 13 months of diagnosis. There is not an extensive description in the literature of the diabetic treatment of GATA6 patients who develop adolescent or adult onset diabetes. In fact there are only 8 cases described and 6 were treated with insulin, one with metformin and one treatment unknown [5, 13-15].

It should be emphasized that the use of targeted NGS for clinical diagnostic testing will increase the number of patients with a confirmed diagnosis of monogenic diabetes. NGS technology enables the potential for simultaneous analysis of all the known disease genes in a single assay at a similar cost to analysing a few genes by Sanger sequencing [17]. Despite the fact that the majority of GATA6 mutations occur de novo, a small number of dominantly inherited cases have been reported [12]. Yorifuji et al. [13] reported the case of a family with a dominantly inherited mutation and neonatal complications resulting in death in 3 of 4 pregnancies. A genetic diagnosis is important since it defines the diagnostic subtype, determines the most appropriate treatment and informs the sibling recurrence risk or risk of GATA6 associated anomalies in offspring.

In conclusion, this report describes a heterozygous novel GATA6 mutation (p.Tyr235Ter) resulting in the clinical picture of congenital heart defects, dorsal pancreas agenesis and adult-onset diabetes in a patient with no first-degree family history of diabetes. It emphasizes the importance of screening the GATA6 gene in young patients with diabetes and congenital cardiac defects. It also highlights the importance of genetic counselling in these patients as future offspring will therefore be at risk of inheriting the variant and possibly developing a much more severe phenotype that could include pancreatic agenesis and congenital heart defects.

\section{Abbreviations}

NGS: Next generation sequencing; TFs: Transcription factors; NDM: Neonatal diabetes mellitus; MODY: Maturity onset diabetes of the young

\section{Acknowledgements}

The authors have no acknowledgements to declare.

\section{Authors' contributions}

B.S-L, wrote the manuscript and designed the Figs. M.S., N.N., C.W., participated in the diagnosis of the patient. K.C., performed genetic analysis and designed Figs. C.W. and M.B., supervised and revised manuscript. All authors discussed the case and commented on the manuscript. The author(s) read and approved the final manuscript.

\section{Funding}

The author(s) received no financial support for the research, authorship, and/or publication of this article.

\section{Availability of data and materials}

All data is available in this manuscript, this case report did not require any analysis. The raw sequencing data has been submitted to NCBI's sequence read archive (SRA). The accession number is SRX7816321 and the link to the data submission.

\section{Ethics approval and consent to participate}

We confirm that written informed consent to participate was obtained from the parents and family members of the proband in the study.

\section{Consent for publication}

We confirm that written informed consent for publication of their clinical details and/or clinical images was obtained from the patient her parents and grandmother.

\section{Competing interests}

The authors declare that they have no competing interests.

\section{Author details}

${ }^{1}$ Department of Diabetes \& Endocrinology, Mater Misericordiae University Hospital, Dublin 7, Ireland. ${ }^{2}$ Department of Diabetes \& Endocrinology, Tallaght University Hospital, Dublin 24, Ireland. ${ }^{3}$ Department of Molecular Genetics, Royal Devon \& Exeter NHS Foundation Trust, Exeter, UK.

Received: 4 July 2019 Accepted: 25 March 2020

Published online: 03 April 2020

\section{References}

1. Villamayor L, Rodriguez-Seguel E, Araujo R, Carrasco M, Bru-Tarí E, MelladoGil JM, et al. GATA6 controls insulin biosynthesis and secretion in adult beta cells. Diabetes. 2018;67:448-60.

2. Viger RS, Guittot SM, Anttonen M, Wilson DB, Heikinheimo M. Role of the GATA family of transcription factors in endocrine development, function and disease. Mol Endorinol. 2008;22:781-98.

3. Molketin JD. The zinc finger-containing transcription factors iGATA-4, -5 and -6 . Ubiquitously expressed regulators of tissue-specific gene expression. J Biol Chem. 2000;275:38949-52.

4. Allen HL, Flanagan SE, Shaw-Smith C, De Franco E, Akerman I, Caswell R, et al. GATA6 haploinsufficiency causes pancreatic agenesis in humans. Nat Genet. 2011:44:20-2.

5. De Franco E, Shaw-Smith C, Flanagan SE, Sheperd MH, International NDM. Consortium, Hattersley AT et al. GATA6 mutations cause a broad phenotypic spectrum of diabetes from pancreatic agenesis to adult-onset diabetes without exocrine insufficiency. Diabetes. 2013;62(3):993-7.

6. Maitra M, Koening SN, Srivastava D, Garg V. Identification of GATA6 sequence variants in patients with congenital heart defects. Pediatr Res. 2010;68:281-5.

7. Yau D, De Franco E, Flanagan SE, Ellard S, Blumenkrantz M, Mitchell JJ. Case report: maternal mosaicism resulting in inheritance of a novel GATA6 mutation causing pancreatic agenesis and neonatal diabetes mellitus. Diagn Pathol. 2017;12:1.

8. Richards S, Aziz N, Bale S, Bick D, Das S, Gastier-Foster J, et al. Standards and guidelines for the interpretation of sequence variants: a joint consensus recommendation of the American College of Medical Genetics and Genomics and the Association for Molecular Pathology. Genet Med. 2015: 17(5):405-24.

9. Chao CS, McKnight KD, Cox KL. Novel GATA6 mutations in patients with pancreatic agenesis and congenital heart malformations. PLoS One. 2015;23: 10(2):e0118449.

10. Lemelman MB, Letourneau L, Greeley SAW. Neonatal diabetes mellitus: an update on diagnosis and management. Clin Perinatol. 2018;45(1):41-59.

11. De Franco E, Flanagan SE, Houghton JA, Allen HL, Mackat DJ, Temple IK, et al. The effect of early, comprehensive genomic testing on clinical care in neonatal diabetes: an international cohort study. Lancet. 2015;386:957-63.

12. Bonnefond A, Sand O, Guerin B. GATA6 inactivating mutations are associated with heart defects and, inconsistently, with pancreatic agenesis and diabetes. Diabetologia. 2012;55(10):2845-7.

13. Yorifuji T, Kawakita R, Hosokawa Y. Dominantly inherited diabetes mellitus caused by GATA6 haploinsufficiency: variable intrafamilial presentation. J Med Genet. 2012;49(10):642-3.

14. Sayoura M, Jacobsen L, Carmody D, Del Gaudio D, Alkorta-Aranburu G, Arndt $K$, et al. Pancreatic histopathology of human monogenic diabetes due to causal variants in KCNJ11, HNF1A, GATA6, and LMNA. J Clini Endocrinol Metab. 2018;103(1):35-45. 
15. Škoric-Milosavljevic D, Tjong FVY, Barc J, Backx PCM, Clur SAB, SpaendonckZwarts K, et al. GATA6 mutations: characterization of two novel patients and a comprehensive overview of the GATA6 genotypic and phenotypic spectrum. Am J Med Genet. 2019:179A:1836-45.

16. Clissold RL, Hamilton AJ, Hattersley AT, Ellard S, Bingham C. HNF1Bassociated renal and extra-renal disease-an expanding clinical spectrum. Nature Rev Nephrology. 2015;11(2):102-12.

17. Ellard S, Lango Allen H, De Franco E, Flanagan SE, Hysenaj G, Colclough $K$, et al. Improved genetic testing for monogenic diabetes using targeted next-generation sequencing. Diabetologia. 2013;56:1958-63.

\section{Publisher's Note}

Springer Nature remains neutral with regard to jurisdictional claims in published maps and institutional affiliations.

Ready to submit your research? Choose BMC and benefit from:

- fast, convenient online submission

- thorough peer review by experienced researchers in your field

- rapid publication on acceptance

- support for research data, including large and complex data types

- gold Open Access which fosters wider collaboration and increased citations

- maximum visibility for your research: over $100 \mathrm{M}$ website views per year

At BMC, research is always in progress.

Learn more biomedcentral.com/submissions 